\title{
Genetic mutations of GJB2 and mitochondrial $12 S$ rRNA in nonsyndromic hearing loss in Jiangsu Province of China
}

\author{
Qinjun Wei ${ }^{1}$, Shuai Wang ${ }^{1}$, Jun Yao ${ }^{1}$, Yajie Lu' ${ }^{1}$, Zhibin Chen ${ }^{2}$, Guangqian Xing ${ }^{2^{*}}$ and Xin Cao ${ }^{{ }^{*}}$
}

\begin{abstract}
Background: Hearing loss is caused by several environmental and genetic factors and the proportion attributed to inherited causes is assumed at $50 \sim 60 \%$. Mutations in GJB2 and mitochondrial DNA (mtDNA) 12S rRNA are the most common molecular etiology for nonsyndromic sensorineural hearing loss (NSHL). The mutation spectra of these genes vary among different ethnic groups.

Methods: To add the molecular etiologic information of hearing loss in the Chinese population, a total of 658 unrelated patients with NSHL from Jiangsu Province of China were selected for mutational screening including GJB2 and mtDNA 125 rRNA genes using PCR and DNA sequencing technology. As for controls, 462 normal-hearing individuals were collected.

Results: A total of 9 pathogenic mutations in the GJB2 and 7 pathogenic mutations in the 12S rRNA gene were identified. Of all patients, 70 had monoallelic GJB2 coding region mutation in the heterozygous state, 94 carried two confirmed pathogenic mutations including 79 homozygotes and 15 compound heterozygotes. The 235 delC appears to be the most common deafness-causing GJB2 mutation (102/658, 15.50\% ). No mutations or variants in the GJB2 exon1 and basal promoter region were found. In these patients, 4 subjects carried the m.1494C > T mutation (0.61\% ) and 39 subjects harbored the m.1555A > G mutation (5.93\%) in mtDNA $12 S$ rRNA gene. A novel sequence variant at m.1222A > $G$ in the $12 S$ rRNA gene was identified, which could alter the secondary structure of the 125 rRNA.

Conclusion: The mutation spectrum and prevalence of GJB2 and mtDNA 125 rRNA genes in Jiangsu population are similar to other areas of China. There are in total $31.46 \%$ of the patients with NSHL carry deafness-causing mutation in GJB2 or mtDNA 125 rRNA genes. Mutation in GJB2 gene is the most common factor, mtDNA 125 rRNA also plays an important part in the pathogenesis of hearing loss in Jiangsu Province areas. The m.1222A > G was found to be a new candidate mutation associated with hearing loss. Our results indicated the necessity of genetic screening for mutations of these genes in Jiangsu patients with NSHL.
\end{abstract}

Keywords: Nonsyndromic hearing loss, GJB2, Mitochondrial 12S rRNA, Gene mutation

\section{Introduction}

Hearing loss is caused by several environmental and genetic factors, and the proportion attributed to inherited causes is assumed at $50-60 \%$ [1]. About $70 \%$ of which are nonsyndromic hearing loss (NSHL) since hearing loss is the only symptom. Genetic hearing loss of nonsyndromic

\footnotetext{
* Correspondence: xing-ga@163.com; caoxin@njmu.edu.cn

${ }^{2}$ Department of Otorhinolaryngology, The First Affiliated Hospital of Nanjing Medical University, Guangzhou Road No.300, Nanjing 210029, P.R. China ${ }^{1}$ Department of Biotechnology, School of Basic Medical Science, Nanjing Medical University, Hanzhong Road No.140, Nanjing 210029, P.R. China
}

form can follow a pattern of autosomal dominant (DFNA), autosomal recessive (DFNB), or X-linked recessive, and mitochondrial inheritance [2].

To date, there are 134 genetic loci and 80 different genes that have been described for NSHL in human [3]. It is believed that alterations in several members of the connexin protein family and mtDNA $12 S$ rRNA contribute to the development of the majority of genetic hearing losses, in which connexin 26 (GJB2) gene mutations are particularly an important cause of NSHL and mainly linked to pattern of autosomal recessive, and the single-

\section{Biomed Central}

(c) 2013 Wei et al.; licensee BioMed Central Ltd. This is an Open Access article distributed under the terms of the Creative Commons Attribution License (http://creativecommons.org/licenses/by/2.0), which permits unrestricted use, distribution, and reproduction in any medium, provided the original work is properly cited. 
nucleotide alteration mtDNA m.1555A $>\mathrm{G}$ has been identified as a major cause of aminoglycoside-induced NSHL [4-8].

It is estimated that there are approximately 20 million babies born every year in China, of whom about 30,000 are expected to have congenital hearing loss [9]. Carrier frequencies of some mutational hot spots associated with NSHL from different areas and ethnic backgrounds have been reported [10-15], but the molecular etiology of NSHL in the Chinese Jiangsu Province population has not been investigated systematically. To further extend the epidemiological data of common gene mutations in Chinese population, we screened the GJB2 and mitochondrial $12 S$ rRNA genes to determine the etiology of hearing loss in Jiangsu Province.

\section{Materials and methods}

\section{Subjects and audiological examinations}

A total of 658 unrelated hearing loss subjects from 6 typical cities of Jiangsu Province, China were collected. All the individuals were recruited to participate in this study by signing a written informed consent as approved by the Ethical Committee of Nanjing Medical University for $\mathrm{Hu}$ man Studies, and to donate a peripheral blood sample. The protocol was reviewed and genetic studies were conducted on two groups: a case group with moderate to profound and NSHL $(\mathrm{n}=658)$ aged $2-45 \quad(11.3 \pm 2.6)$ years, and a control group $(n=462)$ with normal hearing aged $8-34(11.5 \pm 2.9)$ years. The female-male ratio of these groups are $344 / 314$ and $235 / 227$, respectively. The blood samples of 658 cases were obtained from a panel of sporadic hearing loss individuals collected in the Otological Clinics between January 2008 and July 2012, and the 462 control blood samples were gotten from a panel of unaffected individuals in Jiangsu province. All subjects were Han Chinese in origin, and were evaluated through otological examination and audiological evaluations including pure-tone audiometry (Madsen Orbiter 922), immittance (Madsen Zodiac 901), auditory brainstem response (ABR) (Interacoustic EP25), and transient evoked otoacoustic emissions (Madsen Celesta 503). Hearing loss is defined by the level of hearing loss in the better ear for pure-tone threshold average in the speech frequencies 0.5 , 1,2 , and $4 \mathrm{k} \mathrm{HZ}$. Hearing loss of $26-40 \mathrm{~dB}$ was considered mild; 41-60 dB, moderate; $61-80 \mathrm{~dB}$, severe, and more than $80 \mathrm{~dB}$, profound.

\section{Mutational analysis of GJB2 and mitochondrial $12 \mathrm{~S}$ rRNA genes}

The mutations on the GJB2 and mtDNA $12 S$ rRNA genes were selected for molecular analysis in all 658 NSHL cases and 462 normal controls. The genomic DNA was isolated from peripheral blood leukocytes of all participants using
Puregene DNA Isolation Kits (Watson Biotechnologies Inc, Shanghai China). The quality and quantity of purified genomic DNA were determined by gel electrophoresis (0.8\% agarose) and spectrophotometry.

The coding exon (exon 2) and flanking intronic regions of GJB2 gene were amplified by PCR using primers $F$ (5' TTGGTGTTTGCTCAGGAAGA3') and R (5' GGCCTA CAGGGGTTT CAAAT 3'). The GJB2 exon 1, its flanking donor splice site and the GJB2 basal promoter were amplified with the primers $\mathrm{F}$ (5' TGGGGGCACTTGGGGAAC TCA 3') and R (5' GCAGAAACGCCCGCTCCAGAA 3'). DNA fragments of subjects spanning the mtDNA $12 \mathrm{~S}$ $r R N A$ gene were also amplified by PCR with primers: $\mathrm{P} 1 \mathrm{~F}$ (5' CTCCTCAAAGCAATACACTG 3') and R (5' TGCT AAATCCACCTTCGACC 3'); P2 F (5' CGATCAACCTC ACCACCTCT 3') and R (5' TGGACAACCAGCTATCA CCA $\left.3^{\prime}\right)$.

All the PCR products were purified on QIA-quick spin columns (Qiagen, Valencia, CA) and subjected to direct sequencing by BigDye Terminator Cycle Sequencing kit (version v.3.1) and ABI genetic analyzer 3730 (Applied Biosystems, Foster City, CA, USA) attached Sequencing Analysis software (version 3.7). The resultant sequence data of GJB2 gene were compared with the reference sequence of wild type GJB2 (GenBank No. NG_008358.1) and the genotypes of GJB2 gene in all subjects were subsequently analyzed. PolyPhen-2 (http://genetics.bwh.harvard.edu/pph2/) and SIFT (http://sift.jcvi.org/) were used to predict the effect of previously reported and novel missense changes on protein function. The sequencing data of mtDNA $12 S$ rRNA gene were compared with the updated consensus Cambridge reference sequence (GenBank No. AC_000021.2) to identify mtDNA variants. The uniqueness of each mutation was evaluated by comparison with the MITOMAP, and the Uppsala mtDB database.

\section{Phylogenetic analysis and structural analysis of mitochondrial 125 rRNA}

A total of 22 primates' mtDNA $12 S$ rRNA sequences were selected to analyze the interspecific difference by ClustalW. The additional file lists the mammalian species and the accession numbers of the mtDNA $12 S$ rRNA (Additional file 1: Table S1). The conservation index (CI) was calculated by comparing the human nucleotide variants with other 21 primates. The CI was then defined as the amount of species from the list of 22 different primates that have the wild-type nucleotide at that position.

Pathogenicity of the novel variants was also evaluated by predicting the secondary structures of human mtDNA $12 S$ rRNA transcripts with or without the variant using the RNAdraw program (RNAdraw V1.1, http://www.rnadraw.com). 


\section{Results}

\section{GJB2 gene mutations}

As shown in Table 1, there were totally fifteen kinds of different GJB2 variations detected in the patients and controls. Among these, one variant c. $257 \mathrm{C}>\mathrm{G}$ (T86R) in coding region was novel pathogenic mutation that was identified in two deaf siblings compound with c.605ins46 mutation in the exon 2. The two siblings came from a Chinese Han family and suffered from prelingual and nonsyndromic hearing loss. The c.257C > G (T86R) mutation was also predicted to be damaging by PolyPhen- 2 and SIFT. Eight variants including c.35delG, c.109G > A, c.176del16, c.235delC, c.299delAT, c.504insGCAA, c.605ins46 and c.608TC > AA were pathological mutations that has been reported previously. Four nucleotide changes containing c.79G $>$ A, c.101 $\mathrm{T}>\mathrm{C}$, c. $341 \mathrm{~A}>\mathrm{G}$ and c.608 $\mathrm{T}>\mathrm{C}$ were polymorphisms. The category of two nucleotide changes (c.368C $>$ A, c.571 T > C) was unknown (http://davinci.crg.es/deafness/).

The carrier frequencies of deafness-causing GJB2 mutations in our case group were $0.30 \%$ for c.35delG, $2.28 \%$ for c.109G > A, 3.19\% for c.176del16, $15.50 \%$ for c.235delC, 4.71\% for c.299delAT, $0.30 \%$ for c.504insGCAA, $0.30 \%$ for c.605ins 46 and $0.30 \%$ for c.608TC > AA, respectively. Thus, the total carrier frequency of pathogenic GJB2 mutations in the case group was $24.92 \%(164 / 658)$. The 235 delC appeared to be the most common deafness-causing GJB2 mutation $(102 / 658,15.50 \%)$ with the highest allele frequency. While in the control group, only eleven subjects were detected to carry the heterozygous deafness-causing mutations.

The detailed genotypes of the patients and controls were summarized as Table 2. Of all patients, 70 had monoallelic GJB2 coding region mutations in the heterozygous state, 94 carried two confirmed pathogenic mutations including 79 homozygotes and 15 compound heterozygotes. The genotypes-phenotypes correlations of GJB2 gene mutations in 658 patients were shown in Table 3. In the control group, we detected three c.109G > A, two c.176del16, three c.235delC and two c.299delAT heterozygotes, representing $2.38 \%$ of all normal hearing individuals, which coincided with previous study in different control cohorts. No mutations or variants in the GJB2 exon1 and basal promoter region were found in both the case and control groups.

\section{Mitochondrial 12S rRNA gene mutations}

The two DNA fragments spanning the entire coding region of the $12 S$ rRNA gene were amplified by PCR from genomic DNA of all subjects, and each fragment was purified and subsequently analyzed by direct DNA sequencing. The sequencing results were compared with the updated Cambridge consensus sequence. As shown in Table 4, there were totally 30 kinds of nucleotide changes identified in the $12 S$ rRNA gene. All the nucleotide changes were verified by sequence analysis of both strands and appeared to be homoplasmy. Among these, four subjects with severe or profound hearing loss carried the m.1494C $>\mathrm{T}$ mutation. Three of them had a history of exposure to aminoglycosides before deafness. Thirty-nine patients harbored the m.1555A > G mutation. These translate to a frequency of $5.93 \%$ and $0.61 \%$ for the m.1555A>G and $\mathrm{m} \cdot 1494 \mathrm{C}>\mathrm{T}$ mutations in deafness population of Jiangsu Province, respectively. Meanwhile, 6 subjects harbored the known deafnessassociated m.1095 $\mathrm{T}>\mathrm{C}$ mutation and 18 subjects carried the putative pathogenic mutations at position of 961 (m.961insC, m. 961delT and m.961 T > C).

A novel sequence variant, $\mathrm{m} .1222 \mathrm{~A}>\mathrm{G}$ in the $12 \mathrm{~S}$ $r R N A$ gene, was identified in one patient with profound hearing loss. This variant was not found in 462 controls. Furthermore, we used RNAdraw software to analyze the secondary structure of $12 \mathrm{~S}$ rRNA to localize m.1222A > $G$ variant with either a stem or a loop and to analyze if the base changes within stems alter. As shown in Figure 1, the secondary structure of the $12 \mathrm{~S}$ rRNA $\mathrm{m} .1222 \mathrm{~A}>\mathrm{G}$ variant predicted by RNAdraw indicated that the m.1222A $>$ G induced a marked structural alteration in the transcript.

In addition, phylogenetic analysis was performed by comparing the human $12 S$ rRNA nucleotide variants with other 21 primates. As shown in Table 4, conservation index (CI) among the variants ranged from $13.6 \%(\mathrm{~m} .1009 \mathrm{C}>\mathrm{T}$ variant) to $100 \%$ (m.750A $>\mathrm{G}, \mathrm{m} .752 \mathrm{C}>\mathrm{T}, \mathrm{m} .1095 \mathrm{~T}>\mathrm{C}$, m.1222A > G, m.1438A > G and m.1598G > A variants). Of 30 variants, 15 had a CI more than $78 \%, 8$ had a CI between $78 \%$ and $50 \%$, and the remaining had CIs below $50 \%$. In addition to the $\mathrm{m} .1555 \mathrm{~A}>\mathrm{G}$ and $\mathrm{m} .1494 \mathrm{C}>\mathrm{T}$ mutations, the m.789 $\mathrm{T}>\mathrm{C}$ and $\mathrm{m} .1222 \mathrm{~A}>\mathrm{G}$ variants, which were absent in the 462 controls and whose CIs were above $78 \%$, were the putative deafness-associated variants. In contrast, other 9 variants including m.663A $>\mathrm{G}$, m.681 T $>$ C, m.750A $>$ G, m.752C $>$ T, m.827A $>$ G, m.1107 T > C, m.1438A $>$ G and m.1598G $>$ A, which were present in both the case and control groups, appeared to be the polymorphisms even though they had CIs above $78 \%$.

\section{Discussion}

Hearing loss is the most common neurosensory disorder in humans. Approximately half of the cases have a genetic etiology with extraordinary genetic heterogeneity. For many populations, the most common cause for NSHL is mutated Connexin 26, a gap junction protein encoded by the GJB2 gene, which is expressed in the cochlea and may play a role in $\mathrm{K}^{+}$circulation between different partitions in the cochlea. GJB2 gene is composed of 2 exons separated by an intron. Its coding region is entirely contained in exon 2 . The basal promoter activity resides in the first 128 nucleotides upstream of 
Table 1 Variations in GJB2 gene identified in all subjects

\begin{tabular}{|c|c|c|c|c|c|c|c|c|c|c|}
\hline $\begin{array}{l}\text { Nucleotide } \\
\text { change }\end{array}$ & $\begin{array}{l}\text { Amino } \\
\text { acid change }\end{array}$ & Domain & Category & $\begin{array}{l}\text { PolyPhen-2 } \\
\text { prediction }\end{array}$ & $\begin{array}{l}\text { SIFT } \\
\text { prediction }\end{array}$ & Previous report & $\begin{array}{l}\text { Numbers found in } \\
\text { patients ( } N=658 \text { ) }\end{array}$ & $\begin{array}{l}\text { Freq in } \\
\text { patients (\%) }\end{array}$ & $\begin{array}{l}\text { Numbers found in } \\
\text { controls ( } N=462 \text { ) }\end{array}$ & $\begin{array}{l}\text { Freq in } \\
\text { controls (\%) }\end{array}$ \\
\hline c.35delG & Frameshift & IC1 & Pathogenic & N/A & N/A & Yes & 2 & 0.30 & 0 & 0.00 \\
\hline c.79G > A & Val27lle & TM1 & Polymorphism & 1.000 & 0.15 & Yes & 135 & 20.52 & 65 & 14.07 \\
\hline c.101 T>C & Met34Thr & TM1 & Polymorphism & 0.038 & 0.12 & Yes & 3 & 0.46 & 1 & 0.22 \\
\hline c.109G > A & Val37lle & TM1 & Pathogenic & 1.000 & 0.12 & Yes & 15 & 2.28 & 4 & 0.87 \\
\hline c.176del16 & Frameshift & EC1 & Pathogenic & N/A & N/A & Yes & 21 & 3.19 & 2 & 0.43 \\
\hline c.235delc & Frameshift & TM2 & Pathogenic & N/A & N/A & Yes & 102 & 15.50 & 3 & 0.65 \\
\hline$c .257 C>G$ & Thr86Arg & TM2 & Pathogenic & 1.000 & 0.00 & None & 2 & 0.30 & 0 & 0.00 \\
\hline c.299delAT & Frameshift & IC2 & Pathogenic & N/A & N/A & Yes & 31 & 4.71 & 2 & 0.43 \\
\hline$c .341 A>G$ & Glu114Gly & IC2 & Polymorphism & 0.001 & 0.27 & Yes & 25 & 3.80 & 9 & 1.95 \\
\hline c. $368 C>A$ & Thr123Asn & IC2 & Unknown & 0.000 & 0.53 & Yes & 5 & 0.76 & 1 & 0.22 \\
\hline c.504insAAGG & Frameshift & EC2 & Pathogenic & N/A & N/A & Yes & 2 & 0.30 & 0 & 0.00 \\
\hline c.571 T >C & Phe191Leu & EC2 & Unknown & 1.000 & 0.00 & Yes & 4 & 0.61 & 0 & 0.00 \\
\hline c.605ins46 & Stop at aa 202 & TM4 & Pathogenic & N/A & N/A & Yes & 2 & 0.30 & 0 & 0.00 \\
\hline c.608TC > AA & Ile203Lys & TM4 & Pathogenic & N/A & 0.00 & Yes & 2 & 0.30 & 0 & 0.00 \\
\hline c.608 T > C & Ile203Thr & TM4 & Polymorphism & 0.906 & 0.00 & Yes & 2 & 0.30 & 1 & 0.22 \\
\hline Total & & & & & & & 353 & 53.65 & 88 & 19.05 \\
\hline
\end{tabular}

IC intracellular, $T M$ transmembrane, EC extracellular.

The amino acid substitution is predicted damaging by the score of PolyPhen-2 ( 0 being least and 1 being most) and SIFT (ranges from 0 to 1 , damaging $<=0.05$, tolerated $>0.05$ ). 


\section{Table 2 Genotypes of GJB2 gene in patients with hearing loss and controls}

\begin{tabular}{|c|c|c|c|c|c|c|c|c|}
\hline \multicolumn{3}{|l|}{ Allele 1} & \multicolumn{3}{|l|}{ Allele 2} & \multirow[t]{2}{*}{$\begin{array}{l}\text { Numbers found in } \\
\text { patients ( } N=658 \text { ) }\end{array}$} & \multirow[t]{2}{*}{$\begin{array}{l}\text { Numbers found in } \\
\text { controls }(N=462)\end{array}$} & \multirow[t]{2}{*}{$\begin{array}{l}\text { Exon } 1 \text { or splice site } \\
\text { nucleotide change }\end{array}$} \\
\hline Nucleotide change & $\begin{array}{l}\text { Consequence or amino } \\
\text { acid change }\end{array}$ & Category & Nucleotide change & $\begin{array}{l}\text { Consequence or amino } \\
\text { acid change }\end{array}$ & Category & & & \\
\hline c.35delG & Frameshift mutation & pathogenic & - & - & - & 1 & 0 & - \\
\hline c.109G > A & Val37lle & pathogenic & - & - & - & 7 & 3 & - \\
\hline c.176del16 & Frameshift mutation & pathogenic & - & - & - & 6 & 2 & - \\
\hline c.235delC & Frameshift mutation & pathogenic & - & - & - & 40 & 3 & - \\
\hline c.299delAT & Frameshift mutation & pathogenic & - & - & - & 12 & 2 & - \\
\hline c.504insAAGG & Frameshift & pathogenic & - & - & - & 2 & 0 & - \\
\hline c.608TC $>$ AA & Ile203Lys & pathogenic & - & - & - & 2 & 0 & - \\
\hline c.35delG & Frameshift mutation & pathogenic & c.235delC & Frameshift mutation & pathogenic & 1 & 0 & - \\
\hline c. $109 \mathrm{G}>\mathrm{A}$ & Val37lle & pathogenic & C. $109 \mathrm{G}>\mathrm{A}$ & Val37lle & pathogenic & 8 & 0 & - \\
\hline c.176del16 & Frameshift mutation & pathogenic & c.176del16 & Frameshift mutation & pathogenic & 7 & 0 & - \\
\hline c.176del16 & Frameshift mutation & pathogenic & c.235delC & Frameshift mutation & pathogenic & 5 & 0 & - \\
\hline c.176del16 & Frameshift mutation & pathogenic & c.299delAT & Frameshift mutation & pathogenic & 3 & 0 & - \\
\hline c.235delC & Frameshift mutation & pathogenic & c.235delC & Frameshift mutation & pathogenic & 52 & 0 & - \\
\hline c.235delc & Frameshift mutation & pathogenic & c.299delAT & Frameshift mutation & pathogenic & 4 & 0 & - \\
\hline$c .257 C>G$ & Thr86Arg & pathogenic & c.605ins 46 & Stop at aa 202 & pathogenic & 2 & 0 & - \\
\hline c.299delAT & Frameshift mutation & pathogenic & c.299delAT & Frameshift mutation & pathogenic & 12 & 0 & - \\
\hline c.79G $>$ A & Val27lle & polymorphism & - & - & - & 64 & 28 & - \\
\hline c.101 T>C & Met34Thr & polymorphism & - & - & - & 3 & 1 & - \\
\hline c.79G $>$ A & Val27lle & polymorphism & c.79G $>$ A & Val27lle & polymorphism & 49 & 13 & - \\
\hline c. $79 \mathrm{G}>\mathrm{A}$ & Val27lle & polymorphism & c. $341 \mathrm{~A}>\mathrm{G}$ & Glu114Gly & polymorphism & 9 & 1 & - \\
\hline c. $341 A>G$ & Glu114Gly & polymorphism & c. $341 \mathrm{~A}>\mathrm{G}$ & Glu114Gly & polymorphism & 5 & 1 & \\
\hline$c .341 A>G$ & Glu114Gly & polymorphism & c.79G $>$ A & & & & & \\
\hline c. $341 A>G$ & Val27lle & & & & & & & \\
\hline Glu114Gly & polymorphism & & & & & & & \\
\hline polymorphism & 2 & 0 & - & & & & & \\
\hline c.79G $>$ A & Val27lle & polymorphism & c. $368 \mathrm{C}>\mathrm{A}$ & Thr123Asn & unknown & 11 & 3 & - \\
\hline c.608 T > C & Ile203Thr & polymorphism & c. $608 \mathrm{~T}>\mathrm{C}$ & \|le203Thr & polymorphism & 4 & 0 & - \\
\hline c. $368 \mathrm{C}>\mathrm{A}$ & Thr123Asn & unknown & - & - & - & 1 & 1 & - \\
\hline c. $571 \mathrm{~T}>\mathrm{C}$ & Phe191Leu & unknown & - & - & - & 4 & 0 & - \\
\hline
\end{tabular}


Table 3 GJB2 genotypes and phenotypes in the 658 unrelated patients

\begin{tabular}{|c|c|c|c|c|c|}
\hline \multirow[t]{2}{*}{ Genotype } & \multirow{2}{*}{$\begin{array}{l}\text { Number of subjects } \\
\text { with this genotype }\end{array}$} & \multicolumn{3}{|l|}{ Phenotype } & \multirow[t]{2}{*}{ Onset } \\
\hline & & moderate & severe & profound & \\
\hline Biallelic mutations & 94 & & & & \\
\hline c.35delG/c.235delC & 1 & & & 1 & Prelingual \\
\hline c.109G > A/c.109G > A & 8 & 2 & 2 & 4 & Post (2), pre (6) \\
\hline c.176del16/c.176del16 & 7 & & 3 & 4 & Prelingual \\
\hline c.176del16/c.235delC & 5 & & 1 & 4 & Prelingual \\
\hline c.176del16/c.299delAT & 3 & & & 3 & Prelingual \\
\hline c.235delC/c.235delC & 52 & 1 & 11 & 40 & Prelingual \\
\hline c.235delC/c.299delAT & 4 & & & 4 & Prelingual \\
\hline c. $257 C>$ G/c.605ins 46 & 2 & & & 2 & Prelingual \\
\hline c.299delAT/c.299delAT & 12 & 1 & 1 & 10 & Prelingual \\
\hline Heterozygous mutations & 70 & & & & \\
\hline c.35delG & 1 & & & 1 & Prelingual \\
\hline c.109G > A & 7 & 2 & 3 & 2 & Post (3), pre (4) \\
\hline c.176del16 & 6 & & 1 & 5 & Prelingual \\
\hline c.235delC & 40 & 3 & 8 & 29 & Post (8), pre (32) \\
\hline c.299delAT & 12 & 1 & 3 & 8 & Prelingual \\
\hline c.504insAAGG & 2 & & 1 & 1 & Prelingual \\
\hline c.608TC > AA & 2 & 1 & & 1 & Prelingual \\
\hline Polymorphism and unknown & 152 & & & & \\
\hline C.79G > A & 64 & 13 & 22 & 29 & Post (3), pre (61) \\
\hline $\mathrm{c} .101 \mathrm{~T}>\mathrm{C}$ & 3 & 1 & 1 & 1 & Post (1), pre (2) \\
\hline c.79G > A/c.79G > A & 49 & 11 & 15 & 23 & Post (5), pre (44) \\
\hline c. $79 \mathrm{G}>\mathrm{A} / \mathrm{c} .341 \mathrm{~A}>\mathrm{G}$ & 9 & 1 & 1 & 7 & Prelingual \\
\hline$c .341 A>G / c .341 A>G$ & 5 & 2 & 2 & 1 & Prelingual \\
\hline$c .341 \mathrm{~A}>\mathrm{G} / \mathrm{c} .341 \mathrm{~A}>\mathrm{G} / \mathrm{c} .79 \mathrm{G}>\mathrm{A}$ & 2 & & 1 & 1 & Prelingual \\
\hline$c .79 \mathrm{G}>\mathrm{A} / \mathrm{c} .368 \mathrm{C}>\mathrm{A}$ & 11 & 1 & 1 & 9 & Prelingual \\
\hline c.368C > A & 1 & & 1 & & Prelingual \\
\hline c. $571 \mathrm{~T}>\mathrm{C}$ & 4 & & 2 & 2 & Prelingual \\
\hline$c .608 \mathrm{~T}>\mathrm{C} / \mathrm{c} .608 \mathrm{~T}>\mathrm{C}$ & 4 & & 1 & 3 & Prelingual \\
\hline No mutations identified & 342 & 28 & 52 & 262 & \\
\hline Total & 658 & & & & \\
\hline
\end{tabular}

the transcription start point (TSP) and has two GC boxes, at position 281 and 293 from the TSP, which is important for transcription [17]. Previous reports have suggested that the mutation spectrum and prevalence of GJB2 vary significantly among different ethnic groups. GJB2 mutations with the c.35delG, c.167delT, c. $235 \mathrm{delC}$ and c. $427 \mathrm{C}>\mathrm{T}$ alleles were responsible for a large proportion of NSHL in European, American, African and the Asian [18-25]. In the Chinese populations, the $235 \mathrm{delC}$ is responsible for up to $21 \%$ of cases with NSHL [9].

Similar to other previous reports of China $[10,14,26]$, our study showed that GJB2 mutations were an important cause of NSHL in Jiangsu deafness populations, and the most common GJB2 mutation detected in our study group was the c.235delC $(102 / 658 ; 15.50 \%)$. While the c.35delG mutation, which is prevalent in the Caucasians and rarely found in Chinese populations, was identified only in 2 patients. The four most prevalent mutations: c.235delC, c.299delAT, c.176del16, and c.35delG, account for $23.70 \%$ (156/658) of all mutant GJB2 alleles identified in Jiangsu Province. However, no mutations were found in GJB2 basal promoter region and exon 1 or splice sites, which suggested extremely low detection rate of GJB2 basal promoter region and exon 1 or splice sites mutation in this area. 
Table 4 Mitochondrial 12S rRNA variants identified in this study

\begin{tabular}{|c|c|c|c|c|c|c|c|c|c|c|c|}
\hline Nucleotide change & Homo/heteroplasmy & $\begin{array}{l}\text { NSHL } \\
(\mathrm{N}=658)\end{array}$ & $\begin{array}{l}\text { Freq in } \\
\text { patients(\%) }\end{array}$ & $\begin{array}{l}\text { Controls } \\
(\mathrm{N}=462)\end{array}$ & $\begin{array}{l}\text { Freq in } \\
\text { controls(\%) }\end{array}$ & conservation index ${ }^{a}$ & $\begin{array}{l}\text { Chinese } \\
(\mathrm{N}=1642)^{\mathrm{b}}\end{array}$ & $\begin{array}{l}\text { freq in } \\
\text { Chinese(\%) }\end{array}$ & Previous report $^{c}$ & $\begin{array}{l}m \mathrm{mDB}^{\mathrm{c}} \\
(\mathrm{N}=2704)\end{array}$ & $\begin{array}{l}\text { Freq in } \\
\text { mtDB (\%) }\end{array}$ \\
\hline $663 A>G$ & homoplasmy & 4 & 0.61 & 3 & 0.65 & 17/22(77.3\%) & 16 & 1.0 & Yes & 86 & 3.2 \\
\hline $681 \mathrm{~T}>\mathrm{C}$ & homoplasmy & 9 & 1.37 & 6 & 1.30 & 18/22(81.8\% ) & 30 & 1.8 & Yes & 11 & 0.4 \\
\hline 709 G > A & homoplasmy & 143 & 21.73 & 109 & 23.59 & $14 / 22(63.6 \%)$ & 330 & 20.1 & Yes & 444 & 16.4 \\
\hline $735 A>G$ & homoplasmy & 4 & 0.61 & 2 & 0.43 & $16 / 22(72.7 \%)$ & 10 & 0.6 & Yes & 3 & 0.1 \\
\hline $750 A>G$ & homoplasmy & 656 & 99.70 & 460 & 99.57 & $22 / 22(100 \%)$ & 1638 & 99.8 & Yes & 2682 & 96.7 \\
\hline $752 C>T$ & homoplasmy & 16 & 2.43 & 15 & 3.25 & $22 / 22(100 \%)$ & 51 & 3.1 & Yes & 20 & 0.7 \\
\hline $789 \mathrm{~T}>\mathrm{C}$ & homoplasmy & 1 & 0.15 & 0 & 0.00 & 20/22(90.9\% ) & 2 & 0.1 & Yes & 1 & 0.0 \\
\hline $827 A>G$ & homoplasmy & 24 & 3.65 & 13 & 2.81 & 20/22(90.9\% ) & 54 & 3.3 & Yes & 54 & 2.0 \\
\hline 961 ins $C$ & homoplasmy & 15 & 2.28 & 1 & 0.22 & 20/22(90.9\% ) & 25 & 1.5 & Yes & 37 & 1.4 \\
\hline 961 delT + insC & both & 2 & 0.30 & 0 & 0.00 & 20/22(90.9\% ) & 1 & 0.1 & Yes & no data & no data \\
\hline $961 \mathrm{~T}>\mathrm{C}$ & homoplasmy & 1 & 0.15 & 1 & 0.22 & 20/22(90.9\% ) & 3 & 0.2 & Yes & 37 & 1.4 \\
\hline $979 \mathrm{C}>\mathrm{T}$ & homoplasmy & 1 & 0.15 & 0 & 0.00 & 6/22(27.3\% ) & 0 & 0.0 & Yes & 1 & 0.0 \\
\hline $1005 T>C$ & both & 29 & 4.41 & 22 & 4.76 & 9/22(40.9\% ) & 72 & 4.4 & Yes & 7 & 0.3 \\
\hline $1009 C>T$ & homoplasmy & 4 & 0.61 & 3 & 0.65 & $3 / 22(13.6 \%)$ & 10 & 0.6 & Yes & 2 & 0.1 \\
\hline $1040 T>C$ & homoplasmy & 1 & 0.15 & 0 & 0.00 & $8 / 22(36.4 \%)$ & 0 & 0.0 & Yes & 2 & 0.1 \\
\hline $1041 A>G$ & homoplasmy & 6 & 0.91 & 1 & 0.22 & 7/22(31.8\% ) & 11 & 0.7 & Yes & 14 & 0.5 \\
\hline $1048 \mathrm{C}>\mathrm{T}$ & homoplasmy & 17 & 2.58 & 11 & 2.38 & 13/22(59.1\% ) & 48 & 2.8 & Yes & 51 & 1.9 \\
\hline $1095 \mathrm{~T}>\mathrm{C}$ & homoplasmy & 6 & 0.91 & 1 & 0.22 & 22/22(100\% ) & 10 & 0.6 & Yes & 5 & 0.2 \\
\hline $1107 \mathrm{~T}>\mathrm{C}$ & homoplasmy & 46 & 6.99 & 29 & 6.28 & 18/22(81.8\% ) & 103 & 6.3 & Yes & 34 & 1.3 \\
\hline $1119 \mathrm{~T}>\mathrm{C}$ & homoplasmy & 23 & 3.50 & 19 & 4.11 & 13/22(59.1\% ) & 53 & 3.2 & Yes & 26 & 1.0 \\
\hline $1187 \mathrm{~T}>\mathrm{C}$ & homoplasmy & 3 & 0.46 & 1 & 0.22 & $11 / 22(50 \%)$ & 0 & 0.0 & Yes & 1 & 0.0 \\
\hline $1222 A>G$ & homoplasmy & 1 & 0.15 & 0 & 0.00 & 22/22(100\% ) & 0 & 0.0 & None & 0 & 0.0 \\
\hline $1282 G>A$ & homoplasmy & 2 & 0.30 & 0 & 0.00 & 13/22(59.1\% ) & 0 & 0.0 & Yes & 2 & 0.1 \\
\hline $1382 A>C$ & homoplasmy & 17 & 2.58 & 11 & 2.38 & 17/22(77.3\% ) & 43 & 2.6 & Yes & 65 & 2.4 \\
\hline $1415 G>A$ & homoplasmy & 1 & 0.15 & 0 & 0.00 & 8/22(36.4\% ) & 1 & 0.1 & Yes & 1 & 0.0 \\
\hline $1438 A>G$ & homoplasmy & 658 & 100.00 & 461 & 99.78 & $22 / 22(100 \%)$ & 1640 & 99.9 & Yes & 2620 & 96.9 \\
\hline $1494 C>T$ & homoplasmy & 4 & 0.61 & 0 & 0.00 & 18/22(81.8\% ) & 3 & 0.2 & Yes & 1 & 0.0 \\
\hline $1520 T>C$ & homoplasmy & 3 & 0.46 & 0 & 0.00 & $6 / 22(27.3 \%)$ & 6 & 0.4 & Yes & 3 & 0.1 \\
\hline $1555 A>G$ & homoplasmy & 39 & 5.93 & 0 & 0.00 & 20/22(90.9\% ) & 65 & 4.0 & Yes & 12 & 0.4 \\
\hline $1598 G>A$ & homoplasmy & 14 & 2.13 & 10 & 2.16 & $22 / 22(100 \%)$ & 49 & 3.0 & Yes & 67 & 2.5 \\
\hline
\end{tabular}

${ }^{a}$ The conservation index (Cl) was based on the results of the multiple alignment by ClustalW. See Additional file 1: Table S1 for information on the species used to calculate the sequence conservation; ${ }^{\mathrm{b} D a t a}$ from the refrence [15]; 'Uppsala mtDB database [16]. 


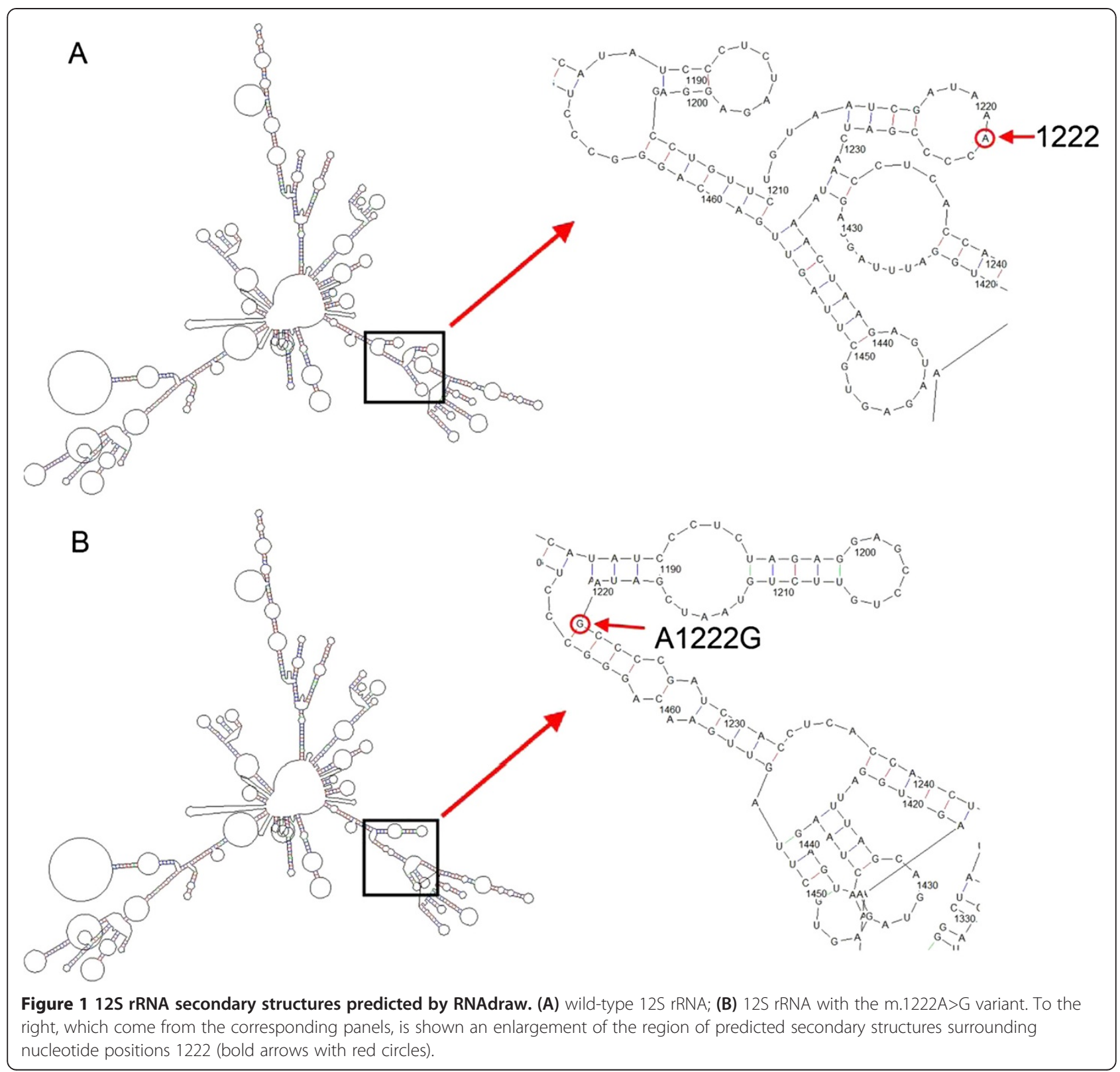

Through genotype analysis in 658 cases of unrelated NSHL of Jiangsu Province, GJB2 mutations were detected in $14.29 \%(94 / 658)$ of patients with biallelic mutation, and $10.64 \%(70 / 658)$ of patients with monoallelic mutation. The reason for the failure to detect a second mutant allele in the 70 cases in the present study claims further clarification.

One novel nucleotide alteration c.257C > G (T86R) in coding region of GJB2 gene were identified in two deaf siblings compound heterozygotes carrying c.605ins 46 pathogenic mutation in the exon 2 of GJB2, this change has not been reported in Connexins and Deafness mutations database at http://davinci.crg.es/deafness/. The heterozygotes were detected from their hearing parents, the father carried c.257C > G (T86R) mutation, while the mother with c.605ins 46 mutation, the opposite alleles of the parents were both wild-type.

Although the majority of cases with NSHL are caused by nuclear gene mutations, it has become clear that mtDNA mutations can also cause deafness. In familial cases of ototoxicity, aminoglycoside hypersensitivity is often maternally transmitted, suggesting that the mutation in mtDNA is the molecular basis for this susceptibility. In the human mtDNA genome, m.1555A $>\mathrm{G}$ is the most common mutation in the gene. The $12 S$ rRNA gene was proposed to be the primary targeting site for aminoglycosides. The identified nonsyndromic deafness-causing mtDNA mutations include m.1555A $>$ G, m.1494C $>$ T, m.1095 $\mathrm{T}>\mathrm{C}$ and 
mutations at position 961 in the 12S rRNA gene [27-32]. Currently, it is estimated that these mutations are present in about $3.10 \%$ of patients with NSHL, but it is expected that this number will increase as genetic testing becomes more readily available. In this study, 658 patients and all controls were screened for mtDNA $12 S$ rRNA gene by PCR and DNA direct sequencing. We detected 30 variants in $12 S$ rRNA gene. Among these, 39 patients carried the mtDNA $12 S$ rRNA m.1555A $>$ G mutation $(5.93 \%)$, which coincided with the previous report [15]. Four patients carried m.1494C $>\mathrm{T}$ mutation, 6 patients carried m.1095 T > C mutation, and 18 patients possess mutations at 961 position. A novel sequence variant, m.1222A > G in the $12 S$ rRNA gene, was identified in one patient with profound hearing loss. Comparison of the variant frequencies in controls, assessment of nucleotide conservation among mammalian species, and structural analysis of the transcript were used to analyze the m.1222A > G mutation associated with hearing loss. To our knowledge, the homoplasmic m.1222A > G variant in 12S rRNA gene has not been reported to date. Conservation of the nucleotide among 22 primates and alteration of the predicted secondary structure of the $12 S$ rRNA transcript suggest that the $\mathrm{m} .1222 \mathrm{~A}>\mathrm{G}$ variant might affect auditory function by changing the function of the $12 \mathrm{~S}$ rRNA.

Similar to that of the GJB2 gene mutations, the association between mtDNA mutations and hearing loss has also a special ethnic and regional difference. In the NSHL cases of Jiangsu population, the incidence of the mtDNA mutation including m.1555A $>$ G, m.1494C $>\mathrm{T}$, m.1095 $\mathrm{T}>\mathrm{C}$ and mutations at position 961 in the $12 \mathrm{~S}$ $r R N A$ gene appears to coincide with other populations as previous reports [15].

In summary, the results of our study indicate that the mutation spectrum and prevalence of GJB2 and mtDNA $12 S r R N A$ genes in Jiangsu patients with hearing loss is similar to other areas of China. There are in total $31.46 \%$ of patients with NSHL carry deafness-causing mutations in GJB2 or mtDNA $12 S$ rRNA gene. Mutation in GJB2 gene was the most common factor, mtDNA $12 \mathrm{~S}$ $r R N A$ also play an important part in the pathogenesis of hearing loss in Jiangsu Province areas. These results indicate the necessity of genetic screening for mutations of these genes in Jiangsu patients with NSHL.

\section{Additional file}

Additional file 1: Table S1. List of animal species and the accession numbers of the mtDNA (GenBank) used to calculate nucleotide conservation.

\section{Competing interests}

The authors declare that they have no competing interests.

\section{Authors' contributions}

XC, GQX and QJW conceived and designed the study. SW, JY, YJL and ZBC performed the experiments and analysis. QJW and SW wrote the original manuscript. XC and GQX contributed to revisions of the manuscript. All authors read and approved the final version.

\section{Acknowledgments}

This research was supported by the Grant from Jiangsu Health Administration of China (L201120) to GQX; the National Natural Science Foundation of China (No. 31171217) and a Project Funded by the Priority Academic Program

Development of Jiangsu Higher Education Institution to XC.

Received: 26 March 2013 Accepted: 1 July 2013

Published: 4 July 2013

\section{Reference}

1. Cohen MM, Gorlin RJ: Epidemiology, etiology and genetic patterns. In hereditary hearing loss and its syndromes. In Origins of Oxford monographs on medical genetics, No 28. Edited by Gorlin RJ, Toriello HV, Cohen MM. New York: Oxford University Press; 1995:9-21.

2. Bitner-Glindzicz M: Hereditary deafness and phenotyping in humans. Br Med Bull 2002, 63:73-94.

3. Hereditary Hearing Loss. [http://hereditaryhearingloss.org].

4. Estivill $X$, Fortina P, Surrey $S$, et al: Connexin-26 mutations in sporadic and inherited sensorineural deafness. Lancet 1998, 351:394-398.

5. Rabionet R, Zelante L, Lopez-Bigas N, et al: Molecular basis of childhood deafness resulting from mutations in the GJB2 (connexin 26) gene. Hum Genet 2000, 106:40-44.

6. Wilcox SA, Saunders K, Osborn AH, et al: High frequency hearing loss correlated with mutations in the GJB2 gene. Hum Genet 2000, 106:399-405.

7. Fischel-Ghodsian N: Genetic factors in aminoglycoside toxicity. Pharmacogenomics 2005, 6(1):27-36.

8. Guan MX: Mitochondrial 12S rRNA mutations associated with aminoglycoside ototoxicity. Mitochondrion 2011, 11:237-245.

9. Yu F, Han DY, Dai $P$, et al: Mutation of GJB2 gene in Chinese nonsyndromic hearing impairment patients: analysis of 1190 cases. Natl Med J China 2007, 87:2814-2819.

10. Dai $P, Y u F$, Han B, et al: GJB2 mutation spectrum in 2063 Chinese patients with nonsyndromic hearing impairment. J Trans/ Med 2009, 7:1-12.

11. Yuan Y, Yu F, Wang G, et al: Prevalence of the GJB2 IVS1 + 1G >A mutation in Chinese hearing loss patients with monoallelic pathogenic mutation in the coding region of GJB2. J Trans/ Med 2010, 8:127.

12. Wang QJ, Zhao YL, Rao SQ, et al: Newborn hearing concurrent gene screening can improve care for hearing loss: a study on 14,913 Chinese newborns. Int J Pediatr Otorhinolaryngol 2011, 75:535-542.

13. Li $Z_{1}$ Li R, Chen J, et al: Mutational analysis of the mitochondrial $12 S$ rRNA gene in Chinese pediatric subjects with aminoglycoside-induced and non-syndromic hearing loss. Hum Genet 2005, 117:9-15.

14. Dai $P$, Liu X, Han D, et al: Extremely low penetrance of deafness associated with the mitochondrial 12S rRNA mutation in 16 Chinese families: Implication for early detection and prevention of deafness. Biochem Biophys Res Commun 2006, 340:194-199.

15. Lu J, Li Z, Zhu Y, et al: Mitochondrial $12 \mathrm{~S}$ rRNA variants in $1642 \mathrm{Han}$ Chinese pediatric subjects with aminoglycoside-induced and nonsyndromic hearing loss. Mitochondrion 2010, 10:380-390.

16. Uppsala mtDB database. http://www.genpat.uu.se/mtDB/.

17. Tu ZJ, Kiang DT: Mapping and characterization of the basal promoter of the human connexin26 gene. Biochim Biophys Acta 1998, 1443:169-181.

18. Brobby GW, Muller-Myhsok B, Horstmann RD: Connexin 26 R143W mutation associated with recessive nonsyndromic sensorineural deafness in Africa. N Engl J Med 1998, 338:548-550.

19. Sun Q, Yuan HJ, Liu X, et al: Mutation analysis of GJB2 in Chinese population with DFNA. Chin Arch Otolaryngol Head Neck Surg 2008, 11:625-627.

20. Tóth T, Kupka S, Haack B, et al: Coincidence of mutations in different connexin genes in Hungarian patients. Int J Mol Med 2007, 20(3):315-321.

21. Reinhard $R$, Trevor $L$, Christian $S$, et al: Relevance of the $A 1555 G$ mutation in the $12 S$ rRNA gene for hearing impairment in Austria. Otol Neurotol 2007, 28:884-886.

22. Kelley PM, Abe S, Askew JW, et al: Human connexin 30 (GJB6), a candidate gene for nonsyndromic hearing loss: molecular cloning, tissue-specific 
expression, and assignment to chromosome 13q12. Genomics 1999, 62:172-176

23. Del Castillo FJ, Rodríguez-Ballesteros M, Alvarez A, et al: A novel deletion involving the connexin-30 gene, del(GJB6-d13s1854), found in trans with mutations in the GJB2 gene (connexin-26) in subjects with DFNB1 non-syndromic hearing impairment. J Med Genet 2005, 42:588-594.

24. Sirmaci A, Akcayoz-Duman D, Tekin M: The c.IVS1 + 1G > A mutation in the GJB2 gene is prevalent and large deletions involving the GJB6 gene are not present in the Turkish population. J Genet 2006, 85(3):213-216.

25. Neocleous V, Aspris A, Shahpenterian V, et al: High Frequency of 35delG Mutation and Absence of del(GJB6-D13S1830) in Greek Cypriot Patients with Nonsyndromic Hearing Loss. Genet Test 2006, 10:285-289.

26. Dai $P, Y u$ F, Han B, et al: The prevalence of the 235 delC GJB2 Mutation in a Chinese Deaf Population. Genet Med 2007, 9:283-289.

27. Del Castillo FJ, Rodriquez-Ballesteros M, Martin Y, et al: Heteroplasmy for the $1555 \mathrm{~A}>\mathrm{G}$ mutation in the mitochondrial 12S rRNA gene in six Spanish families with non-syndromic hearing loss. J Med Genet 2003, 40:632-636.

28. Zhu Y, Li Q, Chen Z, et al: Mitochondrial haplotype and phenotype of 13 Chinese families may suggest multi-original evolution of mitochondrial C1494T mutation. Mitochondrion 2009, 9(6):418-428.

29. Dai D, Lu Y, Chen Z, et al: Co-segregation of the T1095C with the A1555G mutation of the mitochondrial 125 rRNA gene in a patient with nonsyndromic hearing loss. Biochem Biophys Res Commun 2008, 377(4):1152-1155.

30. Xing G, Chen Z, Wei Q, et al: Mitochondrial 12S rRNA A827G mutation is involved in the genetic susceptibility to aminoglycoside ototoxicity. Biochem Biophys Res Commun 2006, 346(4):1131-1135.

31. Bacino C, Prezant TR, Bu X, et al: Susceptibility mutations in the mitochondrial small ribosomal RNA gene in aminoglycoside induced deafness. Pharmacogenetics 1995, 5:165-172.

32. Tang $X$, Yang $L$, Zhu $Y$, et al: Very low penetrance of hearing loss in seven Han Chinese pedigrees carrying the deafness-associated $12 \mathrm{~S}$ rRNA A1555G mutation. Gene 2007, 393:11-19.

doi:10.1186/1479-5876-11-163

Cite this article as: Wei et al:: Genetic mutations of GJB2 and mitochondrial $12 S$ rRNA in nonsyndromic hearing loss in Jiangsu Province of China. Journal of Translational Medicine 2013 11:163.

\section{Submit your next manuscript to BioMed Central and take full advantage of:}

- Convenient online submission

- Thorough peer review

- No space constraints or color figure charges

- Immediate publication on acceptance

- Inclusion in PubMed, CAS, Scopus and Google Scholar

- Research which is freely available for redistribution 